\title{
TRIMALCHIO, CLASSE SOCIAL E ESTAMENTO
}

\author{
Prof: Fábio Faversani \\ Universidade Federal de Ouro Preto
}

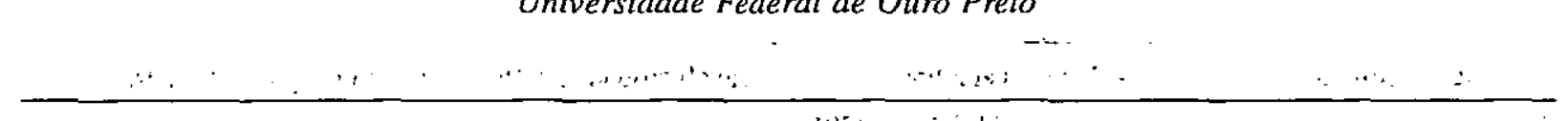

RESUMO: Este 'artigo propõe uma reflexão acerca de elementos conceituais utilizados na análise da história social romana. Para tal, utilizamos uma figura literária construída por Petrônio '(Trimalchio), que foi considerada como típica da sociedáde romana à épocả do Principado por parcela significativa da historiografia. Nossa intenção últimà é ressalitar os limites e possibilidades apreséritados por estès conceitos e refletir sobre a possibilidade de superação de entraves que estes apresentem a uma mais rica compreensāo desta sọciedade. .

ABSTRACT - This article intends to reflect upon some conceptual elements of the analysis of Roman Social History. In order to achieve this goal, we study Petronius' literary character Trimalchio, who is considered typical of Roman society during the period of the Principate by a significant number of historians. Our purpose is to stress the limitations of these concepts and to reflect upon the possibility of overcoming the barrier that they present for a richer understanding of that society.

PALAVRAS-CHAVE: História Romana, História Social, Trimalchio, História e Literatura.

KEY-WORDS: Roman History, Social History, Trimalchio, History and Literature.

\section{Introduçāo}

Nosso objetivo, com o presente trabalho, é apresentar uma rèflexão sobre dois conceitos que têm se' mostrado básicos às análises dá imensa maioria dos historiadores sociais, quais sejam:"'1) o conceito de classe social e 2) o conceito de estamento. Nossa reflexão se dará a partir da tentaiiva de compreender a posição social ocupada por um personagem do Satyricon de Petrônio, Trimalchio, tomando por base os conceitos aludidos.
A escolha de Trimalchio, obviamente, nāo é casual. Elà se explica pelo próprio debate historiográfico que este personagem gerou. Trimalchio foi considerado por inúmeros historiadores como uma figura típica da sociedade romana à época do Principado. Portanto, através dele nāo correremos o risco de estar tomando como exemplo uma figura social singular ou até mesmo "anồmala" para embasar empiricamente nossa reflexão. Outrossim, 
em que pese o virtual consenso relativo à tipicidade de Trimalchio, há, entre os historiadores, uma rica polêmica quanto à questāo da caracterização dessa tipicidade.

Citaremos duas posiçōes que julgamos exemplares da latitude do debate que Trimalchio propicia apenas para exemplificar a riqueza de nosso exemplo, já que não é possível, neste momento, discutir a questão de sua tipicidade em si' . Para ROSTOVTZEFF (1937, t. I, pp. 120 ss.), ele é o lípico representante de uma classe ascendente, mais vinculada ao mercado, e concorrente ou aliada plausível da aristocracia fundiária de Roma; para VEYNE, (1961, pp. 213-247) ele é típico por representar justamente o contrário, ou seja, a demonstração da impossibilidade de os libertos se tornarem um grupo hegemônico, ou mesmo serem admitidos naquele pré-existente por suas limitações jurídicas (condição de ex-escravo, portanto não-cidadão) e culturais (carências da formação cultural erudita, tida como própria aos membros da aristocracia romana de nascimento livre) $)^{2}$.

Assim, temos uma figura duplamente "típica" $\mathrm{e}$ bastante rica do ponto de vista da análise social como base empírica para a reflexão dos conceitos que são objeto de nossa análise.

1. Cf. D'Ams, 1981, pp. 97-120. Para Jean Andreau: os tibertos "são estranhos à época em que vivem: na gama de papéis oferecidos pela sociedade romana, Trimalquião não encontra nenhum para si" (Andreau, 1991, p. 150). Segundo Pedro López Barja de Quiroga: "La discontinuidad en los nomina [de libertos e patronos na epigrafia funerária de Óstia] muestra que en Ostia ( $y$, probablemente, también en Puteoli) hubo pocos Trimalciones". (Quiroga, 1991, p. 174). Segundo Ste Croix. Trimalchio $\varepsilon$ : "in reality [...] a ludicrous series of comic exaggerations". (Ste Croix, 1983, p. 178).

2. Finley, entre muitos outros, endossa a perspectiva de Veyne em A Economia Antiga, Porto, Afrontamento, 1980, p. 44.

\section{Breve retrato de Trimalchio ${ }^{3}$}

Será útil criar um breve retrato de Trimalchio que balize sua classificação social ulterior através dos conceitos de classe social e estamento. Nossa intenção com estes apontamentos não é discutir à exaustão este rico personagem, mas tão somente expor os elementos constitutivos deste para sua utilização aos fins que nos propomos ${ }^{4}$.

Trimalchio é um dos personagens do Satyricon, romance escrito por um consular romano $\mathrm{em}$ meados do século I d. C., do qual nos restou apenas uma parcela de seu conteúdo completo ${ }^{5}$. $O$ fragmento mais

3. Utilizamos o texto estabelecido por Alfred Ernout (Pétrone, Le Satiricon. $10^{\text {emo }}$ éd., Paris, Les Belles Lettres, 1990), sendo as traduçōes de nossa autoria. Os números que aparecem entre parénteses nesta seção se referem à localizaçāo das passagens do Satyricon que julgamos conveniente citar ou apontar para apoiar este "breve retrato de Trimalchio". Não entramos aqui na discussão sobre os exageros que Petrônio cria, com uma intencionałidade cômica, na construção de Trimalchio. Satisfaz-no notar algo obvio: ele é verossímil dentro da sociedade romana do século l, como o demonstra a existéncia de outros libertos que eram mais pode. rosos que Trimalchio e controlavam riqueza comparível à sua (cf. Tác. Ann. XII, 53). Para detalhes veja-se: Alföldy. 1989, pp. 122 ss.; Quiroga, 1991, pp. 163-174: D'Arms, 1974, pp.104124 e a lista das maiores fortunas privadas, compilada por Richard Duncan-Jones (1982, pp. 343-344) a partir das cifras apontadas pelas fontes antigas, na qual, dentre as dez maiores, quatro são de libertos.

4. Assim, algumas polêmicas interessantes nâo serão abordadas por serem neste contexto irrelevantes. Citamos como exemplo, a polêmica sobre se Trimalchio era primordialmente um comerciante, agiota ou latifundiário, bem como àquela que discute se houve significativo crescimento de sua fortuna ou não. Basta-nos, como já foi apontado, que ele seja considerado típico desta socjedade e, portanto, pertinente à análise que empreenderemos.

5. Não nos importa discutir aqui o quanto do Satyticon original nos restou. $O$ debate sobre este tema tem estimado que originalmente a obra deveria ser 6 ou até 12 vezes maior que a atual. Para Santidrián (1987, p. 11 ), seria 6 vezes; para De Guerle (s/d, p. XI), 10; segundo Rat (1934, p. VI), que se apoia em outros autores para tal (Douza e Collingnon) entre 6 e 12; Sullivan (1979, p.13) fala entre 6 e 10 vezes maior. Sobre esta questão concordamos com Alfred Ernout que diz: "En verité, toutes les suppositions qu'en pourra faire à ce sujet ne 
longo da obra é a Cena Trimalchionis. Neste banquete, Petrônio apresenta diversos personagens que, através de suas falas, vão dando ao leitor noçăo de quem são eles e da trajetoria que os conduziu até ali. O personagem exposto com mais detalhes aos olhos do leitor é o anfítriāo, Trimalchio. Trata-se de um homem idoso (XXVIİ, l) que é casado com Fortunata, uma ex-escrava que cuida dos bens de seu marido. Segundo um conviva: "Ele próprio [Trimalchio] não sabe o que possui de tão rico que é; mas aquela filha da māe [Fortunata] sabe de todas as coisas, até o que você nāo imaginaria" . Assim, Trimalchio é um grande proprietário que não tem como preocupação primordial a administraçāo de seus bens, à melhor moda $\mathrm{da}$ aristocracia romana.

Mas, no que consiste a riqueza de Trimalchio? Cremos poder dividi-la em três partes, a fim de expôla: 1) terras e escravos; 2) estrutura comercial e 3) dinheiro entesourado ou emprestado a juros. Destas três parcelas da riqueza de Trimalchio, a primeira é apontada como vastíssima. Diz um conviva: "Trimalchio tem tantas terras quanto pode um gaviāo enxergar em um vôo [...]. Quanto aos seus escravos puxa vida! - creio, por Hércules, que nem um décimo deles conheça seu senhor pessoalmente"7.

Quanto à riqueza investida em atividades comerciais, temos uma fala "casual" de Trimalchio que nos dá suficiente noção de sua amplitude: "Nasci sob [a constelação de] Câncer: e como um caranguejo tenho muitos pés, assim, no mar e na terra muitas coi-

seront jamais que fantaisie et jeu d'imagination. Elles ne peuvent avoir de valeur probante, el n'avanceront pas d'une ligne notre connaissance de Pétrone" (Ernout, 1950, p. XIV).

6. "Ipse nescit quid habeat, adeo saplutus est; sed haec lupatria prouidet omnia, et ubi non putes." (XXXVII. 6)

7. "Trimalchio fundos habet, quantum milui uolant $[. .$. Familia uero - babac babae! non mehercules puto decumam partem esse quae dominum suum nouerit." (XXXVII, 8-9). Cf. ainda: XLVIII, 2-3; LIII, 1-3 e 5-9.8 sas possuo ${ }^{8}$, como um caranguejo que se adapta bem tanto lá quanto cá" .

Por fim, temos sua riqueza em moeda destinada ao empréstimo. Esta riqueza era complementar e se destinava simplesmente a fazer com que o dinheiro não ficasse no caixa sem se fazer rendoso. Os montantes envolvidos são enormes. Em um dia: "foram recolhidos à arca, já que não se pode colocá-los [em empréstimo], cem mil sestércios"10. Segundo um conviva, Trimalchio "tem dinheiro que não acaba mais. A grana guardada no quartinho de seu porteiro é mais do que alguém teria por todo seu patrimônio. [...] Em resumo, coloca no bolso todos estes babacas [referindo-se aos outros convivas]"'1.,12.

Esta proverbial riqueza garantia a Trimalchio auto-suficiência. Tudo quanto consumia fazia produzir em suas propriedades (XXXVI, 1). Deste modo, tinha importantes características comuns ao restritíssimo grupo que na sociedade romana poderia ser visto como a classe dominante ou o estamento hegemônico (como a riqueza, absenteísmo e auto-suficiência). No entanto, não pertencia a ele. Faltava-lhe a condição de cidadão ${ }^{13}$, relaçōes de amizade com homens de grande poder ${ }^{14}$, uma car-

8. Quando ele fala possuir bens no mar, por certo se refere a navios (e cargas) que eram utilizados no comércio de longo percurso.

9. "In cancro ego natus sum: ideo multis sto, et in mari et in terra multa possideo: nam cancer et hoc et lloc quadrat." $(\mathrm{XXXIX,8)}$

10. "in arcam relatum est, quod collocari non potuit, sestcrtium centies." (LIII, 4)

11. Sendo que só um deles possui um patrimônio de oitocentos mil sestércios (XXXVIII, 7).

12. "Nummorum nummos. Argentum in ostiarii illius cella plus iacet, quam quisquam in fortunis habet. [...]. Ad summam, quemuis ex istis babaecalis in rutae folium coniciet". (XXXVII, 8 e 10)zz

13. Mesmo que adaptasse símbolos distintivos de cidadãos das classes censitárias mais altas (cf. XXXI, 3; LX, 8-9; LXXI, 9).

14. Não há referências de que Trimalchio, que tem todos os seus sinais distintivos expostos ao extremo no texto de Petrónio, tivesse relaçōes sequer com um decuriāo do 
reira pública ${ }^{15}$, tradição familiar, controle da cultura erudita ${ }^{16}$ etc.

\section{A classe social de Trimalchio}

Antes de tentarmos classificar Trimalchio segundo o conceito de classe social, cremos serem necessárias algumas palavras sobre o que entendemos sobre este conceito.

Pảra tal é inevitável perceber que desde a obra marxiana - que o cita por diversas vezes sem ter nunca ter chegado a definí-lo (ELSTER, 1989, p. 166) o conceito de classe social passou por inúmeras cri- . ticas e reformulaçōes que trouxeram boa dose de confusão a quem procura definí-lo de forma mais universal. No entanto, parece-nós possível estabelecer que o conceito de classe social visa organizar os diveršos agentes e compreender suas possibilidade de ação coletiva a partir da constatação de que ocupam uma posição similar na estrutura de uma determinada sociedade. Para ser possível tal diagnóstico, é ne-

municipium provinciano $\mathrm{cm}$ que se encontrava. A relação de amicitia mais elcvada que estabeleceu é com Habinnas, um marmoreiro. Isso se torna ainda mais importante se notarmos que o banquete se passa no litoral campaniano, onde os libertos tinham uma inserçāo social bastante considerável. Cf. Quiroga, 199i, pp. 163-174. Ainda que Jean Andreau (1991, pp. 147-165) afirme que os "notáveis" não admitiam estabelecer relações de amizade com libertos, a falta de uma eficiente comprovação dessa sua impressão a faz ficar sem maior valor. '

15. Ainda que Trimalchio procure "falsificar" o cumprimento de atividades públicas (XXX,.1-4, LXXI, 9) e, paradoxalmentc, afirmasse não desejar exercê-las (LXXI, 12).

16. Sua ignorância é freqüentemente exposta, bem como sua afinidade com atitudes atribuiveis a individuos grosseiros (cf. XXIX, 9: L, 2 ss.; LI1,3; LII, 9-10; LII1, 12-13: LV; LIX, 3; LXXIII, 3), ainda que pretenda a todo momento se mostrar erudito (cf. L, 2: LIX, 3) e, a exemplo do que acontece com a carreira política, afirme desprezar o mecanismo de formação utilizado pelos indivíduos considerados eruditos (LXXI, 12). cessário tomar alguma variável, ou variáveis, que propiciem o ordenamento lógico do corpo social"?

Parece-nos que quatro variáveis têm tido emprego largamente preponderante ${ }^{18}$. Examinemo-las uma a uma, perguntando-nos em que classe social encontraríamos Trimalchio através de sua aplicação.

A primeira e, sem dúvida, a mais difundida, classifica os ágentes pelo controle ou não dos meios de produção ${ }^{19}$. Scgundo este critério, Trimalchio pertenceria à classe dos latifundiários romanos por deter bens de raiż em quantidade invejável.

A segunda variável se refere à posiçāo dos agentes nas relaçōes de expploração do trabalho, criandose, assim, três classes possíveis, formadas por: 1) aqueles que trabalham menos do que seria necessá: rio para produzir o que obtém no processo produtivo; 2 ) aqueles que trabalham mais do que obtém e 3 ) aqueles que trabalham aproximadamente o equivalente ao que obtérn. Novamente, empregando este critério, Trimalchio estaria na classe dominante, a par dos senadores romanos.

Derivado deste, temos um terćeiro meio de ordenar os agentes em classes sociais que se funda na relação dos agentes no mercado de trabalho. Neste caso teríamos, mais uma vez, três classes sociais identificáveis: 1) a dos que compram força de trabaIho; 2) a dos que vendem e 3 ) a dos que não com. pram nem vendem, garantindo uma situação de au-

17. Desde que não ocorra uma "infinita fragmentaçăo" (cf. Elster, que se remete a Marx: an. cit. p.167), que tiraria a utilidade analítica do concejto.

18. Para a definiçảo do conceito de classe, seguimas de perto as proposiçōes feitas por Elster a respeito (1989, pp. 165. 187 e 1991, pp. 319-344).

19. Utilizamos o termo controle, ao invés de propriedade, por assim incluir altos dirigentes de propriedades corporativas (como a eclesística) ou das sociedades anônimas, em especial as transnacionais que, embora não sejam proprietários dos meios de produção, controlam os bens que thes garantem uma posição social elevada. 
tonomia em relação a este mercado. De novo, teríamos em Trimalchio um membro da classe dominante.

Por fim, um quarto critério traça divisōes de classes segundo o poder dos diversos agentes nas relações de trabalho. Por este critério teríamos também três classes: 1) os que controlam (altos dirigentes); 2) os que são controlados (trabalhadores) e 3) os que têm superiores e subordinados (posições de comando intermediárias e inferiores). Mais uma vez, Trimalchio pertenceria, sem dúvida, à classe dominante.

Portanto, Trimalchio, rico proprietário de terras e escravos, controlador de meios de produção e de seres humanos, pertenceria, segundo a aplicação do conceito, à classe dominante romana. Ele, que foi conduzido à condição de membro da classe exploradora e poderosa pelo uso do conceito de classe social, não a ocupava concretamente. Mesmo que tenhamos em vista formas diversas de compreender a sociedade romana, parece-nos claro que faltam-the caracteres fundamentais à posição que conceitualmente ocuparia (ALFÖLDY, 1989, pp. 130-148; MACMULLEN, 1986, pp. 85 e 98-101; ANDREAU, 1991, pp. 160 e 163-164; VEYNE, 1961, pp. 213-247; GARNSEY \& SALLER, 1982, p. 24; FUNARI, 1994, p. 31). Ou seja, em que pese Trimalchio se situar em uma "posição estrutural" bastante privilegiada, isto não garante uma equivalência com respeito a sua concreta situação sóciopolítica, para a qual săo relevantes características superestruturais das quais carecia, como já ressaltamos.

Assim, parece-nos mais razoável pensar que o conceito de classe social se mostra, na melhor das hipóteses, insuficiente para a análise da sociedade romana, visto ser incapaz de compreender um elemento social que é considerado típico desta sociedade. É preciso lembrar que uma definição nāo faz uma teoria e que um conceito pode ser reconstruído a fim de garantir uma mais geral e confiável aplicabilidade.
No entanto, tal como se apresenta hoje, $e$ necessário atestar que o conceito de classe social tem uma utilidade altamente discutível para a história social roma$\mathrm{na}^{20}$.

\section{O estamento de Trimalchio}

A exemplo do que fizemos quando examinamos o conceito de classe, exporemos, sucintamente, o que entendemos pelo conceito de estamento. Tendo gerado muito menos polêmica que o anteriormente discutido, cremos ser possível retomá-lo a partir da compreensão que teve dele o autor que inspirou a muitos em seu emprego, ou seja, Max Weber.

Utilizaremo-nos das palavras do próprio Weber para estabelecer nossa definição, procurando verificar se Trimalchio pode ser clássificado através deste conceito de forma satisfatória:

Em oposição à situação de classe, condicionada por motjvos puramente econômicos, chamaremos de situą̧ão estamental todo componente típico do destino dos homens que é determinado por uma estimativa social específica negativa ou positiva - da honra." (GERTH \& MILLS, 1947, pp. 186-187)

Se consideramos "como estimativa social da honra" a condição de ex-escravo, por certo Trimalchio poderia ser percebido como membro de um estamento, o dos libertos. Sigamos, assim, com a definição weberiana:

Tanto individuos proprietários, quanto nāo-proprietários, podem constituir um mesmo estamento e freqüentemente isto acontece com consequeências muito apreciáveis. (GERTH \& M!LLS, 1947, p. 187)

20. Confome já apontavam as críticas feitas por marxistas aos limites deste conceito $\mathrm{em}$ um artigo (Annequin, Clavel-Lévêque \& Favory, 1979, pp. 5-54, em especial, p. 14), já antigo, que não receberam soluções satisfatórias até aqui. 
Entāo pertenceriam ao mesmo estamento de Trimalchio, tanto libertos ricos como era seu próprio caso, quanto aqueles miseravelmente pobres. Avancemos então:

Em resumo, a honra estamental é normalmente expressa por, antes de tudo, um estilo de vida que deve se esperar de todos aqueles que integram este círculo fechado, objetivando, assim, restringir a mobilidade 'social' (ou seja, aquela mobilidade nāo submetida a motivaçōes econômicas ou comerciais). Estas restriçðes podem reduzir os casamentos ao interior do próprio estamento $\mathrm{e}$ podem levar a um completo fechamento endogâmico. (GERTH \& MILLS, 1947, pp. 187-188)

Se fôssemos atribuir um estilo de vida a Trimalchio, certamente teríamos que atentar a três pontos básicos: 1) a precariedade de seus conhecimentos no campo da cultura erudita; 2 ) a ausência de atividades vinculadas à vida pública e; 3 ) afastamento em relação a uma tradição familiar a ser cultivada.

Quanto ao primeiro aspecto do "estilo de vida" de Trimalchio, teremos que excluir do estamento dos libertos alguns indivíduos que pertenciam ao mesmo status jurídico do personagem petroniano. Já que devemos considerar a existência de libertos que escaparam a este "estilo de vida", como os escravos - potenciais libertos - formados pelos senhores na funçāo de educar os filhos da mais fina clite romana, ou os escravos educados desde a infância pelos senhores para serem um símbolo de poder (como o próprio Trimalchio os tinha, sem conseguir torná-los eruditos por suas obvias limitaçōes), entre inúmeros outros casos (RAWSON, 1985, pp. 6 ss.; VEYNE, 1961, p. 220), como o de Terêncio, um dos maiores comedígrafos romanos e que era um liberto.

Da mesma forma, teríamos que excluir alguns indivíduos ao examinar o concernente ao afastamento em relação à carreira pública. Vários libertos a praticaram, em especial na condição de decuriōes das cidades que encontravam dificuldades para recrutar, entre os membros livres (ingenui) de seu municipium, elementos dispostos a financiar o evergetismo que se exigia dos pretendentes ao cargo $^{21}$, sem contar com os Augustales, que rião se poderá tratar como desprezíveis, mesmo que não tenham poder decisório sobre assuntos municipais.

Além disso, pela aplicação do conceito, todos os caracteres vinculados à superexposiçāo de sua riqueza deveriam ser desconsiderados para a tentativa de "compreensão de ações coletivas" empreendidas por Trimalchio, já que a riqueza não é elemento fundamental para a divisão estamental (conforme vimos Weber explicitar acima) e, ainda, porque a imensa maioria dos libertos não tinham riquezas em quantidade suficiente para praticá-la. Destaque-se que esta superexposição da riqueza $\mathfrak{c}$ uma das características mais marcantes de Trimalchio.

Além destas flagrantes limitações do conceito de estamento para garantir a compreensão de Trimalchio, o que surge como mais significativo nesta - passagem refere-se à impossibilidade de se pensar em uma estabilidade estamental dos libertos, devido a peculiaridade de não se reproduzirem geneticamente e, portanto, carecerem de um elemento fundamental de perpetuação de um "estilo de vida". Ora, o filho de um liberto é de status jurídico livre e, assim, cria uma instabilidade dada pela renovaçāo familias completa de seus membros a cada geração, sendo difícil pensar que tal conjunto de indivíduos se torne um estamento no sentido atribuído ao conceito. Não

21. Em 24 d. C., a lex Visellia proibiu este acesso dos libertos ds magistraturas municipais, ainda que, se pensarmos no grande número de transgressōes a esta lei no Baixo lmperio, seja possivel imaginar que scu efeito tenha sido limitado mesmo logo após o infcio de sua vigência. Ainda que seja uma hipótese razóavel, esta teria que ser comprovada para se tornar um argumento mais sólido. Ainda assim, é certo que muitos libertos alavancaram a carreira política de seus filhos, influindo, de forma indireta, em um universo que estar-lhes-ia fechado. Cf. Quiroga, 1991, 163-174; D'Arms, 1974, pp. 104-124; Andreau, 1973, pp. 213-254. 
há perspectiva de estruturação de um "estilo de vida" marcante que sobreviva com este nível de renovação, em especial se pensarmos que quase todos seus membros chegam ao "estamento" na idade adulta. Além disso, independe da vontade dos membros do estamento o ingresso de novos elementos, já que a manumissāo era de competência externa a eles, ou seja, dependia de senhores e escravos ${ }^{22}$.

Seguindo com a definição weberiana:

O desenvolvimento do estamento é essencialmente uma questão de estratificaçāo resultante de uma usurpação na maior parte das vezes. Tal usurpação é origem nomal da maior parte da honra estamental. Mas o caminho que liga a situação puramente convencional a um privilégio legal positivo ou negativo - é facilmente trilhado tão logo quanto uma determinada estratificação tenha de fato sido 'vivida' e tenha obtido estabilidade em virtude de uma estável distribuição do poder econômico. (GERTH \& MILLS, 1947, p. 188)

Aqui é bastante difícil determinar que espécie de "usurpação" teria sido praticada para se criar o estamento dos libertos. A obtenção da condição de liberto junto a um senhor tem motivações cuja variabilidade $\epsilon$ enorme e nâo creio ser possível atribuir a nenhuma delas a condição de usurpadora. Além disto, e mais importante, novamente a idéia de estabilização de um grupo de indivíduos na condição de libertos com pequeno grau de renovação é, por definição, impossível. Assim, um componente importante do conceito inexiste, pois, para Weber, as ações conjuntas săo dadas pelo "sentimento que têm os que agem de pertencerem a um conjunto" (GERTH \& MILLS, 1947, p. 183), "com a exclusão deliberada dos estranhos como o outro lado da moeda" (SEDI,

22. E claro que os libertos podiam interferir em casos particulares, quer comprando a liberdade de escravos, quer tibertando ou não escravos seus. Mas isto nâo altera o fundamental: $o$ ingresso de novos membros nāo estava sobre controle exclusivo do próprio "estamento".
1973, p. 45) ${ }^{23}$. Não é possível saber quem é o outro lado da moeda: os escravos, os livres pobres, a elite senatorial, os eqüestres? Eu não arriscaria uma proposição neste sentido e não saberia, igualmente, como explicar tomando o conceito de estamento, que os libertos urbanos tenham agido várias vezes em conjunto com escravos e livres pobres urbanos, como, por exemplo, nos distúrbios que acometeram Roma durante as Guerras Civis do final da República (BRUNT, 1981, pp. 87-117), e não tenham empreendido nenhuma ação coletiva com libertos rurais que estariam supostamente do mesmo lado da moeda. Não teria explicação igualmente para responder porque Petrônio colocou, como convivas de Petrônio, membros do outro lado da moeda como os scholastici Agamnemnon, Encolpio e Ascilto. Do mesmo modo, não vemos como encontrar uma posição estamental dos libertos quanto a "uma estável distribuição do poder "econômico" que caberia aos libertos no quadro da sociedade romana.

Como fizemos com o conceito de classe, somos obrigados a atestar os grandes limites encontráveis na aplicação do conceito de estamento que, se pode ser maravilhosamente aplicado para compreender a elite senatorial, $e$ ineficiente em relaçâo aos libertos e, certamente, se mostraria ainda mais limitado se aplicado aos ingenui romanos ou aos não-cidadãos livres pobres do Império ${ }^{24}$.

Ainda mais, cumpre destacar que, a bem da verdade, a noção de estamento para a Antigüidade tem

23. Que cita Weber, Max Economía y Sociedad, México, Fondo de Cultura Económica, 1948, t.1, pp. 245 ss. para sustentar suas palavras.

24. Esta diferente adequação da utilidade do conceito weberiano às elites parece-nos explicável, ao menos em parte, pela própria concepção elitista do autor quanto às possibilidades de intervenção dos membros de uma sociedade na definição de seus rumos (cf. Weber, 1993). Para Weber (1993, p. 126): "Não é a 'massa' politicamente passiva que forja o dirigente, mas é o dirigente político que conquista seus segui- 
sido utilizado, em geral, de forma muito mais pobre do que aquela proposta por Weber. Comumente o que se vê é a criação de uma confusão entre estamento e categorias de status jurídico ${ }^{25}$, ou seja, a recriação de uma categoria específica de divisāo do corpo social estabelecida pelos antigos com uma finalidade e gê nese específicas cuja transformação em categoria sociológica estabelece uma readequação de cuja validade duvidamos tanto em sua utilidade analítica, quanto nos interesses que parecem motivar sua utilização (LÉVÊQUE, 1972, pp. 71-93; CARDOSO, 1988, p. 13).

dores e, através da 'demagogia', conquista a massa". Seguindo este raciocínio, parece-nos igualmente razoável pensar que os limites deste conccito no campo da história social da Antigüidade só não têm sido colocados mais claramente devido à predominância de abordagens elitistas nesta áren (cf. Funari, 1989, pp. 9-10 e 73.75), quando nāo claramente precon. ceituosas em relação aos setores menos favorecidos das socicdades clássicas. Citamos, apenas a título de exemplo, algumas passagens de autores com perspectivas analíticas bastante diversas: "So quem trabalhava era a gentinha; as pessoas de bem exerciam em todas as coisas uma atividade de direçäo" (Veyne, 1990, p.137). Esta afirmaçño de Veyne acerca dos grupos sociais livres da Roma Imperial menos privilegiados socialmente, não the exclusiva. Rostovizeff, a quem Veyne se opôs quanto a Trimalchio, antes dele já dizia que: "Da vida das classes inferiores da época (séc. I a.C.) nada sabemos, mas é pouco provável que tivesse atraçōes éspeciais" (Rostovtzeff, 1967. p. 160). Mesmo autores que se debruçaram sobre estas "clas. ses inferiores" não apontaram para proposiçōes mais valorizadoras destes grupos enquanto objeto de estudo: como exemplo disto temos Catherine Salles que os estudou e diz: "Bandidos, escroques ou prostitutas esı̃o longe de constituírem 'categorias sócio-profissionais': nåo passam da escória das sociedades harmoniosas; não passam da escória das sociedades harmoniosas e bem organizadas, uma escória cada vez maior, que ia invadindo o mundo antigo e o teria submergido se esse não tivesse erguido barreiras capazes de conter a Jadroagem e a miséria numa espécie de no man's land" (Salles, 1982, p. 281). E. Badian, por sua vez, afirmou que: "o estudo da Repú. blica Romana - e, em grande parte, também do Império - não $\epsilon$. basicamente o escudo de suas massas nem tampouco o das grandes personalidades: $€$ substancial mente o estudo de suas classes dominantes" (Badian, 1968, p. 92, apud Funari, 1989).

25. Para citar um exemplo que conheceu grande difusão: Petit, 1976. pp. 79 ss, e 155 ss.

\section{Nem classe social, nem estamento. Há uma}

\section{alternativa?}

Por tudo o que vimos, não há como discordar das palavras escritas por Finley:

Em conclusão, podemos demonstrar que, atualmente [1963], com relação a este tópico em particular [taxionomia social], o uso de rólulos e conceitos encontra-se $\mathrm{em}$ um estágio insatisfatório, no qual a terminologia incongruente reflete uma confusão mais profunda quanto à interpretação das próprias instituiçōes. (FINLEY, 1989, p. 62)

No entanto, sua proposição de superação do impasse causado por esta constatação não nos parece razoável. Consubstanciada na idéia de um continuum social (FINLEY, 1980, pp. 88 ss. e 1983, pp. 116-132) que impossibilita a construção de quadros comparativos, a não ser inspirados na confiança do bom "inștinto" do pesquisador, e reduz a pesquisa histórica a um exacerbado empirismo, ou pior, ao "achismo" livremente autorizado ${ }^{26}$.

Outra tentativa de construir uma alternativa para este impasse é proposta por Paul Veyne em seu Como se Escreve a História, que encontrou notável difusão em nosso país. Quanto aos graves limites revclados pelas proposições do autor não é necessário dizer mais do que se lê na recensão de A. CARANDINI

26. Autorizando nossas conclusōés, afirma: "Não é de surpreender que tentativas de classificação boas ou más, dependam de considerações teóricas ou subjacentes" e, por isso, "não são suficientes as classificaçōes." (Finley, 1991, pp. 73-74). Deste modo nâo conseguimos encontrar sentido ern palavras como as de Roland Étienne (1992, p. 376) que, em resenha ao último livro de Finley (Sur l'Histoire Ancienne. Paris, Éditions la Découverte. 1987, coin traduçāo publicada pela Martins Fontes, de São Paulo, em 1994), escreveu: "Si F. Bráudel disait ne pas écrire une ligne sans avoir au préable relu une page de $K$ : Marx, notre génération d'antiquisants ne devrait pas prendre la plume sans relire les textes de M. I. Finley". 
(1979, pp. 329-354) ${ }^{27}$ que demonstrou cabalmente as graves limitaçōes das proposiçōes epistemológicas de Veyne para uma compreensão totalizante da História. Além das proposiçōes de Veyne em seu "ensaio de epistemologia", temos um retrato de sua efetiva aplicação em um livro menos conhecido no Brasil. Em Le Pain et le Cirque ${ }^{28}$ o autor reedita os limites de sua perspectiva como se encarregaram de demonstrar, desta feita, Peter GARNSEY $(1991,164-168)^{29} \mathrm{e}$ ANDREAU, SCHNAPP e SCHMITT $(1978,307-325)^{30}$

Outra alternativa interessante no campo da hist6ria social da Antigüidade é apresentada pelo grupo conhecido como os "vernantiants". Para se notar os limites impostos pela sua importante proposta de revisão metodológica quanto ao aspecto específico que discutimos, basta lembrar que dois de scus mais importantes representantes não conseguiram chegar a um acordo sobre se os escravos constituem ou não uma classe social (VIDAL-NAQUET, 1989, pp. 86-97 e VERNANT, 1992, pp. \&\&) $)^{31}$. Este desacordo de-

27. Para Carandini: "Cotidianidade e psicologismo estão bem delimitados. Assim, para o autor (Veyne), a cotidianidade É a cotidianidade das classes dirigentes", (p. 341) e, ainda, "Quando entre economia e história, entre matéria e espírito se cria um abismo, é sinal que não se quer compreender o real na sua totalidade pelo temor de mudar a ordem social existente (temor inconfessável, ainda que muitas vezes confessado)." ( $p$. 354). A crítica de Carandini nāo conhece, curiosamente, traduçāo para o português.

28. Deste livro Veyne deu uma antecipação em artigo publicado em Annales (1969, pp. 785-825).

29. O autor chama atenção para a contradição entre a pretensa sustentação do trabalho na conceituação e erudição, quando VEYNE deixa a desejar em ambas (pp. 166-168), além de utilizar seu já conhecido estilo: "V. é um polemista descompromissado. Além disso, é um escritor difícil, por ser difuso e "fuyant'." (p. 168).

30. As críticas feitas a sua obra por membros da sua própria "escola" foi ainda mais aguda do que aquela de Gamsey. Para estes: "O método de Pain et le cirque é mais uma técnica de escritura do que um sistema de análise. [...] O livro é, do começo ao fim, conflituoso - como é a posição de um erudito que se fecha em seu gabinete de humanista para as 'drogues' mais' importantes do século" (p. 323). monstra o nível de importância que é dado por estes excelentes historiadores à questão da taxionomia social.

Vamos ficando, assim, pela inadequação de nossos conceitos, condenados ao puro empirismo no que se refere à taxionomia social? Neste ponto do debate parece-nos muito importante retomar as palavras de Pierre Lévêque:

a permanência de uma atitude - refugiada, com uma essência positivista, $\mathrm{cm}$ quadros estritamente jurídicos revelam claramente também o uso de conceitos! - apresentados como cspecíficos e naturais, seguindo diretamente um Aristóteles ou um Cícero, sem que seja colocada jamais a questāo da gênese e da finalidade do direjto e de suas categorias. [...] Só o método marxista permitc conduzir, para além das aparências, uma análise total $^{32}$, já que, partindo de todos os aspectos da realidade histórica, revela o níveis complexos de articulação e coloca cm evidência as relaçōes genéticas e estruturais que eslabelecem entre si no desenvolvimento dialético da história. (LÉVÊQUE, 1972, 77 e 86-87)

Ainda que não possamos concordar com o brilhante historiador francês no que concerne ao marxismo ter que se fundamentar necessariamente em uma Economia Política ${ }^{33}$ que tenha por base o conceito de classe, já que, como vimos, este traz sérios limites para os quais não conseguimos ver uma soluçāo satisfatória, e, diga-se de passagem, problemas que há décadas tem-se tentado solucionar, a nosso ver, sem sucesso. No entanto, é importante destacar a rẹlevância do que nos diz Lévêque sobre o perigo maior do empirismo exacerbado que nada explica $\mathrm{e}$

31. Note-se que ambos ocuparam a direçāo do "Centre de Recherches Comparées sur les Sociétés Anciennes", tendo Vidal-Naquet substituído Vernant.

32. Cf. Cardoso, 1988, pp. 10 ss.

33. Uma excelente defesa da Economia Política encontra- . se em Cardoso (1988, pp. 8-10), com o qual concordamos quando afirma que: "a questão central consiste em saber.se existem ou não, nas sociedades pré-capitalistas, regularidades estruturais passíveis de teorização. Acredito que sim." (p. 9) 
preserva os pré-conceitos dos antigos (CARDOSO, 1988 , p. 13), garantindo um arsenal ideológico que as elites contemporâneas têm sabido recriar e aproveitar (FUNARI, 1989, pp. 74-75).

Neste sentido, parece-nos proveitoso - obviamente, aos pesquisadores preocupados cm compreender a história social antiga em uma perspectiva transformadora - procurar encontrar mecanismos alternativos de compreensão da formação de grupos sociais que estabeleçam ações coletivas a partir de marcos metodologicos alternativos àqueles estabelecidos pelo conceito de classe social.

Assim, surge como promissora uma perspectiva de análise fundada nas relações diretas de poder (GARNSEY \& SALLER, 1987, pp. 148-159) que propiciaria, por um lado, possíveis soluções às críticas levantadas ao conceito de classe e, por outro, garantiria, se empregada de uma forma múltipla, pensada como redes de relações, ao invés de forma binomial, a criação de grupos sociais que garantissem as categorias analíticas neccssárias à comprecnsão das ações coletivas.

\section{Conclusão}

Retomando resumidamente tudo que vimos, cremos poder concluir que: 1. a história social apresenta uma séria crise metodológica no que se refere à taxionomia social e à capacidade de compreendermos as ações coletivas em sociedades da Antigüidade; e que 2. há três soluções básicas para este

\section{Bibliografia}

ALFöldy, Géza. Histơria Social de Roma. Lisboa, Presença, 1989. impasse: a. reduzir as análises ao empirismo, saindo dele apenas através de "insights", cuja comprovação detida ou possibilidade de utilização para fins comparativos mais amplos são limitadíssimas; b. seguir tentando utilizar uma categoria analítica, ou seja, a de classe social, cujos limites têm se mostrado, até aqui, insuperávcis; ou c. buscar criar uma categoria analítica altcrnativa que possa satisfazer as necessidades de compreensão das potencialidades ou efetiva ocorrência de ações coletivas dos agentes sociais. Por tudo quanto vimos, cremos que a primeira solução para o problema só é solução para aqueles que nāo sāo partidários de uma história científica e transformadora, inviabilizada nos marcos apontados por esta; a segunda é positiva mas encontra limites para os quais nāo encontramos solução possível; restando, assim, a terceira, que tem um mérito decisivo: praticamente nāo tem sido experimentada e que, por nos parecer promissora, é uma perspectiva de análise que merece ser testada.

\section{Agradecimentos}

Gostaria de agradecer a Pedro Paulo Abrcu Funari c Norberto Luiz Guarinello que fizeram valiosas sugestōes e críticas ao manuscrito deste artigo e a Adriano S. L. da Gama Cerqueira e Marco Aurélio Santana pelas discussões que muito cooperaram para clarificar algumas de minhas idéias. Os equívocos e incorreções remanescentes são de minha inteira responsabilidade.

ANDREAU, Jean. "O Liberto". In: GIARDINA, Andrea $O H o$ mem Romano. Lisboa, Presença, 1991, pp. 147.165. 
"Remarques sur la société pompéienne (à propos ds tablettes de L. Caccilius Jucundus". Dialogue d'Archeologia, 2-3, 1973, pp. 213-254.

SCHMITT, Pauline \& SCHNAPP, Alain. "Paul Veyne et l'évergétisme". Annales ESC 33, 1978, pp. 307-325.

ANNEQUiN, J., CLAVEL-LÉVÊQUE, M. \& FAVORY, F. "Formas de Explotación del Trabajo y Relaciones Sociales en la Antigüedad Clásica". In: AAVV. Formas de Explotación del Trabajo y Relaciones Sociales en la Antigüedad Clásica. Madrid, Akal, 1979, pp. 5-54

BRUNT, P.A. "Plebe Urbana". In: FINLEY, M.I. (ed.) Essudios sobre Historia Antigua. Madrid, Akal, 1981, pp. 87-117.

CARANDINI, Andrea. Archeologia e Cultura Materiale. Dai "Lavori Senza Gloria" nell'Anlichità a una Politica dei Beni Cultirali. Bari, De Donato Editore, 1979.

CARDOSO, C. F. S. "Economia e Sociedades Antigas. Conceitos e Debates". Classica, 1, 1988, pp. 5-19.

D'ARMS, J. H. "Putcoli in the Second Century of the Roman Empire: a Social and Economic Study". Journal of Roman Studies 64, 1974, pp. 104-124.

"The 'Tipicality' of Trimalchio". In: Commerce and Social Standing in Ancient Rome. Cambridge (Mass.), Harvard University Press, 1981, pp. 97-120.

DE GUERLE, J.N.M. "Recherches sceptiques sur le Satyricon et son autor". In: PÉTRONE. Oeuvres Complètes de Pẹ́trone. Traduit par M. Héguin de Guerle. Paris, Garnier Frères, s/d. pp. VII-XLV.

DUNCAN-JONES, Richard. The Economy of the Roman Empire. Quantitarive Studies. $2^{\text {nd }}$ ed. Cambridge, Cambridge University Press, 1982.

ELSTER, Jon. "Tres Desafios al Concepto de Clase Social". $m$ : ROEMER, John E. (comp.). El Marxismo: Una Perspectiva Analítica. México, Fondo de Cultura Económica, 1989, pp. $165 \cdot 187$. 1991.

ÉTIENNE, Roland. "Compte réndu à FINLEY, M.I. Sur l'Histoire Ancienne. Paris, Éditions La Découverte, 1987." Ann. ESC 47, 2, 1992, pp. 376-377.

FINLEY, M. I. "Between Slavery and Freedom". In: Economy and Society in Ancient Greece. Harmondsworth, Penguin, 1983, pp. 116-132.

Escravidäo Antiga e ldeologia Moderna. Rio de Janeiro, Graal, 1991.

A Economia Antiga. Porto, Afrontamento, 1980.
Uso e Abuso da História. São Paulo, Martins Fontes, 1989.

FUNARI, Pedro Paulo Abreu. Cultura Popular na Antigüidade Clássica. Sāo Paulo, Contexto, 1989.

Roma. Vida Pública e Vida Privada. São Paulo, Atual, 1994.

GARNSEY, P. \& SALLER, R. The Early Principate. Augustus $t o$ Trajan. Oxford, At Clarendom Press, 1982.

The Roman Empire, Economy, Sociery and Culture. London, Duckworth, 1987.

GARNSEY, Peter. "The generosity of Veyne". Journal of Roman Studies 81, 1991, pp. 164-168.

GERTH, H.H. \& MILLS, C. Wright. From Max Weber: Essays in Sociology. London, Kegan Paul, Trench, Trubner \& Co. Ltd., 1947.

LÉVÊQUE, Pierre. "Problèmes téoriques de l'histoire et sociétés antiques" (Entretien avec P.L., par MarieLuce Hazebroucq). In: AA.V V. Aujoud'hui l'Histoire. Paris, Éditions Sociales, 1972, pp. 71-93.

MaCMULLEN, Ramsey. Les Rapports entre les Classes Sociales dans l'Empire Rumain. 50 av. J.-C. 284 ap. J.-C. Paris, Seuil, 1986.

PETIT, Paul. La Poz Romana. Barcelona, Labor, 1976.

PÉTRONE. Le Satiricon. $10^{\circ}$ éd. Texte traduit et établi par Alfred Emout. Paris, Les Belles Lettres, 1990.

QUIROGA, Pedro López Barja de. "La Dependencia Económica de los Libertos en el Alto Imperio Romano". Gerión 9, 1991, pp. 163-74.

RAT, Maurice. "Introduccion". In: PÉTRONE. Satiricon. Traduit par Maurice Rat, Paris, Gamier Frères, 1934. pp. I-XXVIII.

RAWSON, Elisabeth. Intellectual Life in the Late Roman Republic. London, Duckworth, 1985.

ROSTOVTZEFF, M. História de Roma. Rio de Janeiro, Zahar, 1967.

Historia Social y Económica del Imperio Romano. 2 tt. Madrid, Espasa-Calpe, 1937.

SALLES, Catherine. Nos Submundos da Antigüidade. Sāo Pau. lo, Brasiliense, 1982.

STE CROIX, GEM. The Class Siruggle in the Ancient Greek World. 2' ed. London, Duckworth, 1983.

SANTIDRIÁN, P.R. “Introducción”. In: PETRONIUS. Satiricón. Madrid, Alianza, 1987, pp. 7-24.

SEDI, Hirano. Castas, Estamentos e Classes Sociais em Marx 2 Weber. São Paulo, Alfa-Omega, 1973.

SULLIVAN, J.P. "Introduction". In: PETRONIUS and SENECA. 
- The Saryricon and The Apocolocyntosis. Harmonsdworth, Penguin, 1979, pp. 9-26.

TACITI, Cornelii. Annalium ab Excessu Diui Augusti Libri 19 reimpr. Recognouit breuique adnotatione critica instruxit $C$. D. Fischer. Oxford, Oxonii e Typographeo Clarendoniano, 1986.

VERNANT, J.-P. "A luta de classes". In: VERNANT, J.-P. \& VIDAL-NAQUET, P. Trabalho e Escravidão na Grécia Anrigo Campinas, Papinus, 1989, pp. 77-85.

VEYNE, Paul. "Le Vie de Trimalcion". Annales ESC. 16. 1961. pp. 213-247.

"Panem et Circenses: l'évergétisme devant les sciences humaines" Annales ESC 24, 1969, pp. 785-825.
Comment on Écrire l'Histoire. Essai d'épistémologie. Paris, Seuil, 1971.

História da Vida Privada. São Paulo, Cia. das Letras, 1990, vol. I.

Le Pain et le Cirque. Sociologie Historique d'un Pluralisme Politique. Paris, Seuil, 1976.

VIDAL-NAQUET, P. "Os Escravos Gregos Constituíam uma Classe?". In: VERNANT, J.-P. Trabalho e Escravidāo no Grécia Antiga. Campinas, Papirus, 1989. pp. 86-97.

WEBER, Max. Economía y Sociedad. 94 reimpr. de la 24 ed. Mexico, Fondo de Cultura Económica, 1992.

Parlamento e Governo na Alemanha Reordenada. São Paulo, Vozes, 1993. 